\title{
Health, employment, and financial outcomes in workers with occupational asthma
}

\author{
P F G Gannon, D C Weir, A S Robertson, P Sherwood Burge
}

\begin{abstract}
Objective-To study the health, employment, and financial outcome of occupational asthma.

Design-A follow up study of workers with confirmed occupational asthma.

Setting-A specialist occupational lung disease clinic.

Subjects-All workers had a diagnosis of occupational asthma made at least one year earlier. Diagnosis was confirmed by serial peak expiratory flow measurement, specific bronchial provocation testing, or specific immunology.
\end{abstract}

Main outcome measures-Respiratory symptoms, medication, pulmonary function, employment state, and financial position.

Results-112 of a total of 140 eligible workers were followed up. $32 \%$ of patients remained exposed to the causative agent. These workers had more symptoms at follow up than those removed and a greater number were taking inhaled steroids. Continued exposure was also associated with a fall in \% predicted forced expiratory volume in one second $\left(F V_{1}\right)$ of $3 \%$ compared with that at presentation. Their median loss of annual income due to occupational asthma was $35 \%$. Those removed from exposure were worse off financially (median loss $54 \%$ of annual income), had fewer respiratory symptoms than the group who remained exposed, and their \% predicted $F E V_{1}$ had improved by $4 \cdot 6 \%$. Statutory compensation and that obtained by common law suits did not match the loss of earnings due to the development of occupational asthma. Of the workers removed from exposure, those who no longer complained of breathlessness had been diagnosed significantly earlier after the onset of their first symptom

Occupational Lung Disease Unit, Chest Research Institute, East Birmingham Hospital, Birmingham B9 5ST

P F G Gannon, D C Weir, A S Robertson, P Sherwood Burge
(48 $v 66$ months, $p=0.001$ ) and had a significantly higher $\mathrm{FEV}_{1}$ at presentation $(90 \% v 73 \%$ predicted, $p=0.008$ ) compared with those who were still breathless. They had developed symptoms earlier after first exposure (48 $v 66$ months, $p>0.05$ ) and had been removed from exposure sooner (eight $v 12$ months, $p>0.05$ ).

Conclusion-Removal from exposure after diagnosis of occupational asthma is beneficial in terms of symptoms and lung function, but is associated with a loss of income. Early diagnosis is important for symptomatic improvement after removal from exposure. Inadequate compensation may contribute to the workers' decision to remain exposed after diagnosis.

(British fournal of Industrial Medicine 1993;50:491-496)

As asthma is defined as a reversible disease, removal of the causative agent in occupational asthma might be expected to lead to complete recovery. Unfortunately, several follow up studies have shown that this does not usually occur. Studies involving isocyanate workers have shown that after variable periods those removed from exposure still have symptoms. ${ }^{1-4}$ For example, Losewicz et $a l^{2}$ followed up isocyanate workers for four years or more after removal from exposure. They found that only $18 \%$ had no symptoms and $54 \%$ of the workers with symptoms required treatment for asthma at least once a week. In a follow up study of electronic workers with asthma due to colophony fumes Burge $^{5}$ found that only $10 \%$ had no symptoms one to four years after removal from exposure.

Several studies have examined in detail workers who did improve. In a longitudinal follow up study of workers with asthma due to snow crab processing Malo et $a l^{6}$ looked at the period over which improvement might continue. They concluded that the mean time to the plateau of improvement for pulmonary function after removal from exposure was one year. In follow up studies of workers with asthma due to western red cedar Chan-Yeung and co-workers ${ }^{78}$ reported that those who had no symptoms at follow up had significantly higher initial 
lung function, less bronchial hyper-reactivity, a shorter duration of symptoms before diagnosis, and a shorter period of exposure before the development of symptoms than workers who still had symptoms. Smoking did not seem to affect the outcome of these workers. Hudson $e t a l^{9}$ also found a higher baseline $\mathrm{FEV}_{1}$ and a shorter duration of exposure after the onset of symptoms to be significant prognostic factors for recovery for workers who had been exposed to various agents.

Studies of workers sensitised to the complex salts of platinum have produced variable results. A study in a platinum refinery suggested that workers who developed asthma improved when removed from exposure, few having symptoms or a positive skin test to platinum over a year later. ${ }^{10}$ This favourable prognosis is thought to reflect the refinery's routine surveillance, which removes workers from exposure as soon as skin tests become positive to platinum salts or the first symptoms occur. By contrast, a study by Baker et al ${ }^{11}$ showed persisting symptoms and sensitisation after removal from exposure; however, surveillance for skin sensitivity and rapid removal from exposure on their development did not occur in this study.

Some studies have considered the socioeconomic consequences of a diagnosis of occupational asthma. ${ }^{12-14}$ Venables et al ${ }^{12}$ reported that among workers with occupational asthma due to various agents loss of earnings of up to $£ 5000$ had occurred. Rosenberg et $a l^{13}$ found that older workers were more likely to remain exposed after diagnosis because of the difficulties inherent in finding new jobs for this group. Yassi ${ }^{14}$ found that $95 \%$ of workers removed from exposure had long term income loss.

Our study has looked at respiratory symptoms, lung function, employment state, and financial well-being of a large group of workers with occupational asthma due to a number of different agents. A comparison of those workers removed from exposure who complained of breathlessness with those who were no longer breathless at follow up has been made to determine prognostic factors.

\section{Methods}

One hundred and forty workers with a diagnosis of occupational asthma made at least one year earlier were identified from the records of a specialist occupational lung disease clinic. Diagnosis was based on a history of respiratory symptoms that improved on days away from work plus at least one other confirmatory investigation (serial peak expiratory flow (PEF) measurement, bronchial provocation tests, or specific IgE radio allergosorbent test (RAST)).

Each worker was sent a self administered ques- tionnaire by post. It requested information on respiratory symptoms (in an MRC style format), employment state, and current financial situation (including compensation). Diagnostic data, respiratory function, and causative agent were obtained from the workers' case records. Non-responders were sent a further copy of the questionnaire or if still attending the clinic were asked to complete it at their next appointment. Causative agent, duration of exposure, smoking state, and respiratory function on presentation were obtained from the case records of those workers who no longer attended the clinic and had failed to return the questionnaire.

Preparation of the data involved the use of normal plots and the Shapiro Wilkes test of normality. ${ }^{15}$ Parametric data are presented as means and $95 \%$ confidence intervals (95\% CIs) with analysis by pooled or separate variance two tailed $t$ tests for continuous data. Non-parametric data are presented as medians and ranges and analysed by the Mann-Whitney $U$ test for continuous data. $\chi^{2}$ was used for categorical data.

Comparisons were made between workers who remained exposed and those removed from exposure. For workers removed from exposure comparisons were made between those who were not breathless at follow up and those with an MRC breathlessness score of 1 or above-that is, those who were breathless hurrying on level ground or walking up a slight hill.

\section{Results}

One hundred and twelve (80\%) workers completed the questionnaire. Table 1 gives the characteristics of the group. Of the workers who failed to return a questionnaire $26(93 \%)$ case records were traced, so that some information was obtained. Table 2 shows the agents the workers were exposed to at the time of diagnosis. Fifty three per cent of these were recognised for statutory compensation ${ }^{1617}$ in the United Kingdom before the 1991 changes. ${ }^{18}$

The figure shows the distribution of the lag time from first exposure to the development of the first symptoms. Confirmation of the diagnosis was by serial measurement of PEF in $73(65 \%)$, specific bronchial provocation tests in six $(5 \%)$, and specific IgE RAST in eight (7\%). A combination of serial PEF measurements and bronchial provocation tests was used in the remaining $25(23 \%)$.

Thirty four $(30 \%)$ workers still worked in the same job in the same company, $23(21 \%)$ for the same company but in a different job, $16(14 \%)$ for a different company in a different job, and 39 (35\%) were no longer employed. Of those no longer employed $16(41 \%)$ were unemployed, 17 ( $44 \%)$ had taken early retirement due to ill health, 
Table 1 Characteristics of the follow up group. Information as available is shown for the group who were not followed up

\begin{tabular}{llc}
\hline & Workers followed up & Workers not followed up \\
\hline No & 112 & 26 \\
Age (y) & $48(18-72)$ & $42(19-42)$ \\
Men & $83(74 \%)$ & $19(73 \%)$ \\
Never smoked & $35(32 \%)$ & \\
Ex-smokers & $49(44 \%)$ & $14(56 \%)$ \\
Current smokers & $27(24 \%)$ & $15 \cdot 8(6 \cdot 68-24 \cdot 9)$ \\
Pack-years (95\% CI) & $24 \cdot 4(20 \cdot 0-28 \cdot 8)$ & \\
Median time from diagnosis to follow up (months) & $17(12-96)$ & \\
Median time from first exposure to first symptom (months) & $92(14$ days-372) & \\
Median time from first symptom to diagnosis (months) & $18(0-372)$ & $36(3-438)$ \\
Presenting FEV (\% predicted) (95\% CI) & $73(67-79)$ & $76(65-87)$ \\
Presenting FVC (\% predicted) (95\% CI) & $84(78-90)$ & $91(83-99)$ \\
\hline
\end{tabular}

Ranges are shown unless otherwise stated; pack -years = number of 20 cigarette packs a day multiplied by the number of years smoked.

and six (15\%) were on chronic sick leave. Of those who had changed job $58(78 \%)$ said this was because of occupational asthma. The median lag time between diagnosis and changing job was 12 months (range -36 to 36 months; one worker presented for the first time three years after he had changed his job because of symptoms).

Those who remained exposed were compared with those who were no longer exposed in terms of respiratory symptoms and medication (table 3), and lung function at presentation and at follow up (table 4). The two groups were similar for age, sex, and smoking history but the mean time between measurement of pulmonary function of 35 months in the exposed group and 12 months in the group no longer exposed was significantly different $(p=0.003)$. Forty one $(66 \%)$ of those who were no longer exposed thought that their symptoms had improved. Most still had symptoms and were on medication. The forced expiratory volume in one second $\left(F E V_{1}\right)$ in the group who remained exposed fell by $2 \%$ of predicted $(95 \%$ CI $-7 \cdot 23$ to $3 \cdot 23$ ) whereas in the group removed from exposure it improved by $5 \%(95 \%$ CI 0.77 to 8.43$)(p=0.06)$. There was no significant difference in the number exposed in either group to any one of the five most common agents when agents were compared individually by means of a $\chi^{2}$ test.

Fifty six (74\%) of those who had changed job thought that they had lost money because of reduced income as opposed to $14(44 \%)$ who remained exposed. The median perceived annual loss was $£ 3888$ (range $£ 20$ to $£ 10500$ ) in the group removed from exposure and $£ 2533$ (range $£ 67$ to $£ 7000$ ) in the group who remained exposed. The median perceived loss as a percentage of annual income was $54 \%$ (range $9 \%$ to $100 \%$ ) in the unexposed group and $35 \%$ (range $6 \%$ to $65 \%$ ) in the group who remained exposed.

Fifty eight $(47 \%)$ of the follow up group had attempted to claim statutory compensation for occupational asthma of which $27(52 \%)$ had settled the claim, 17 (33\%) had claims outstanding, and eight $(15 \%)$ had had the claim rejected. The median amount of compensation awarded was $£ 1500$ per annum (range $£ 300$ to $£ 1800$ ). Forty five $(41 \%)$ had filed a common law suit against the company where asthma started of which nine $(20 \%)$ had settled the claim, $34(75 \%)$ had claims outstanding, and two $(4 \%)$ had had the claims rejected. The median lump sum compensation awarded was $£ 3500$ (range $£ 500$ to $£ 4000$ ).

Table 5 compares indices for workers who have no breathlessness with those with breathlessness after removal from exposure, in an attempt to identify prognostic factors. Again there was no significant difference in either group in the number exposed to any one of the five most common agents when agents were compared individually by a $\chi^{2}$ test.

\section{Discussion}

This was a large, predominantly male middle aged population who had had an objectively confirmed diagnosis of occupational asthma made between

Table 2 Agents to which workers were exposed at the time of diagnosis. The agents from the group who were not followed up were obtained from their case records

\begin{tabular}{lll}
\hline & $\begin{array}{l}\text { Workers } \\
\text { followed up } \\
\text { No (\%) }\end{array}$ & $\begin{array}{l}\text { Workers not } \\
\text { followed up } \\
\text { No (\%) }\end{array}$ \\
\hline Isocyanates & $27(24)$ & $6(23)$ \\
Oil mists & $14(12)$ & $4(15)$ \\
Colophony & $9(7)$ & $3(12)$ \\
Humidifiers & $8(7)$ & $2(8)$ \\
Flour & $7(6)$ & $2(8)$ \\
Chrome & $6(5)$ & \\
Acid anhydrides & $4(4)$ & \\
Laboratory animals & $2(2)$ & $1(4)$ \\
Aluminium solder & $2(2)$ & \\
Formaldehyde & $2(2)$ & $1(4)$ \\
Polyethylene & $2(2)$ & $2(8)$ \\
Hard metal & $2(2)$ & $5(19)$ \\
Dust & $2(2)$ & \\
Wood dust & $2(2)$ & \\
Other & $12(11)$ & \\
Unknown & $11(10)$ & \\
\hline
\end{tabular}




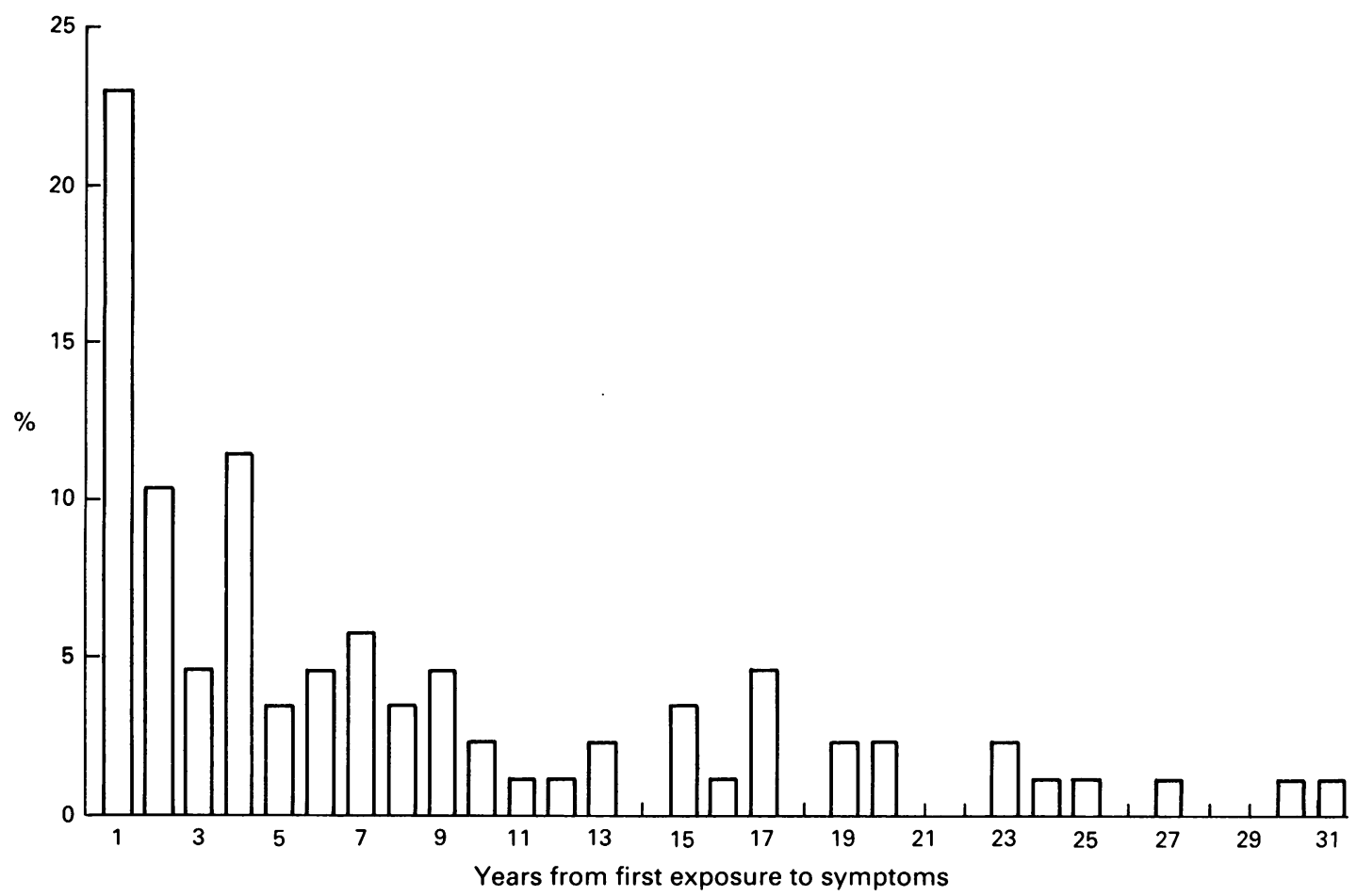

Time from first exposure to the development of symptoms.

one and eight years previously. Unlike most other studies the agents to which the workers were exposed at the time of diagnosis were mixed. The agents were generally well recognised sensitising agents, but less well recognised ones such as chrome and humidifier antigens were also used. Most workers had a history of appreciable cigarette smoking and $25 \%$ were current smokers. The proportion of current and ex-smokers was higher than in other follow up studies of workers with occupational asthma. The median lag time from exposure to the development of symptoms was long at eight years probably underrepresenting those who develop asthma soon after first exposure and leave employment without seeking medical advice. A substantial number had developed symptoms within the first three years in keeping with other studies. ${ }^{19}$

The median delay between the development of symptoms and diagnosis was 18 months, but this was sometimes much longer; 31 years in one case. Confirmation of occupational asthma as the cause of suggestive symptoms was made by serial measurement of PEF in most cases. Thirty per cent of workers continued to be exposed in the same job; $41 \%$ were no longer employed. A minority had been able to change job either within the company or by a move elsewhere. Of those who had left their original job occupational asthma was the usual reason. Some workers had changed job before presenting to the clinic, others took up to three years from diagnosis.

Most of those who were removed from exposure

Table 3 Symptoms, smoking state, and antiasthma treatment in workers with occupational asthma who were removed from exposure and those remaining exposed

\begin{tabular}{lll}
\hline & $\begin{array}{l}\text { Still } \\
\text { exposed } \\
(\%)\end{array}$ & $\begin{array}{l}\text { No longer } \\
\text { exposed } \\
(\%)\end{array}$ \\
\hline No & 34 & 78 \\
Age at follow up (y) (95\% CI) & $48(45-52)$ & $48(45-51)$ \\
Men & $23(68 \%)$ & $60(77 \%)$ \\
Ex/current smokers & $22(65 \%)$ & $54(70 \%)$ \\
20 cigarette pack-years & $20(1-45)$ & $22(1-80)$ \\
Chronic bronchitis (MRC) & $16(47 \%)$ & $37(49 \%)$ \\
Cough & $26(77 \%)$ & $52(68 \%)$ \\
Infrequent wheeze & $32(94 \%)$ & $66(87 \%)$ \\
Frequent wheeze & $20(61 \%)$ & $42(57 \%)$ \\
Breathlessness on level ground & $20(59 \%)$ & $61(78 \%)$ \\
Morning breathlessness & $23(67 \%)$ & $46(64 \%)$ \\
Work related symptoms & $25(78 \%)$ & $28(56 \%)$ \\
Inhaled steroids and bronchodilators & $27(84 \%)$ & $55(78 \%)$ \\
No antiasthma treatment & $2(6 \%)$ & $3(4 \%)$ \\
\hline
\end{tabular}

${ }^{\star} \mathrm{p}<0.05$.

Frequent wheeze $=$ wheeze on most days or nights; work related symptoms are expressed as \% of those still employed in the group no longer exposed. 
Table 4 Pulmonary function in workers with occupational asthma removed from exposure and remaining exposed

\begin{tabular}{lcl}
\hline & Still exposed & No longer exposed \\
\hline No & 34 & 78 \\
Presenting FEV & $82(73-91)$ & $76(71-81)$ \\
Presenting FVC $_{\text {Follow up FEV }}$ & $96(90-102)$ & $90(85-95)$ \\
Follow up FVC $_{\text {Difference between presenting and follow up FEV }}$ & $79(73-87)$ & $81(76-86)$ \\
Median time between pulmonary function in months (range) & $97(97-102)$ & $94(90-99)$ \\
\hline
\end{tabular}

Values are $\%$ predicted $(95 \% \mathrm{CI})$ unless stated otherwise.

Table 5 Comparison between workers with no breathlessness and those who have an MRC breathlessness score of at least 1 after removal from exposure

\begin{tabular}{llll}
\hline & No breathlessness & Breathlessness \\
\hline No & 17 & 61 \\
Age (y) (95\% CI) & $44(35-53)$ & $49(46-52)$ \\
Men & $14(82 \%)$ & $46(75 \%)$ & \\
Smoking & $7(41 \%)$ & $16(27 \%)$ & $\mathrm{p}>0 \cdot 10$ \\
20 cigarette pack-years & 21 & $66(0 \cdot 5-372)$ & $\mathrm{p}=0 \cdot 07$ \\
Symptoms lag (months) & $48(1-360)$ & $24(0-312)$ & $\mathrm{p}=0 \cdot 03$ \\
Diagnosis lag (months) & $5(0-359)$ & $12(-36$ to 36$)$ & $\mathrm{p}=0 \cdot 008$ \\
Change of job lag (months) & $8(-12$ to 24) & $73(67-79)$ & $\mathrm{p}=0 \cdot 07$ \\
Presenting FEV (\% predicted) (95\% CI) & $90(79-101)$ & $88(83-93)$ & \\
Presenting FVC (\% predicted) (95\% CI) & $99(86-112)$ &
\end{tabular}

Symptoms lag = time from first exposure to first symptom; diagnosis lag = time from first symptom to diagnosis; change of job lag = time from diagnosis to change of job; range in parentheses unless otherwise stated.

considered that their symptoms had improved, although most still had symptoms. When the group removed from exposure was compared with those remaining exposed, fewer continued to cough, wheeze, or have morning breathlessness and fewer took an inhaled steroid and a bronchodilator. More of them were breathless, however, when walking on level ground and had symptoms of chronic bronchitis. They had less respiratory symptoms related to work, but $53 \%$ still complained of those symptoms raising the possibility of continued exposure to the sensitising agent. This suggests that those less severely affected were more likely to remain exposed in the same job.

Both groups had abnormal pulmonary function with obstructive defects over the period of observation. A small reduction was seen in the lung function of those who remained exposed and a small improvement in those who were removed from exposure; these changes approached significance $(p=0.06)$. The mean time between readings of pulmonary function was shorter in the group removed from exposure. The data of Malo et al suggest that this should not influence our results. They found that the mean plateau of improvement in pulmonary function was 12 months. In our study there was at least this amount of time between presentation and follow up $\mathrm{FEV}_{1}$ in all workers.

More workers who had changed jobs thought that they had suffered financially compared with those who remained exposed. Those who stayed exposed suffered financially because of sickness, lack of promotion, or reduced opportunity for overtime. The financial loss was generally higher than that seen in other studies. The percentage income lost was considerable in both groups.

Most of those who were eligible had attempted to claim statutory compensation. Half of these were still waiting for a result or had had their claim rejected and the mean annual settlement fell well below the estimated loss of earnings. Forty per cent had filed common law suits but most were outstanding. The average settlement, although higher than statutory compensation, still fell below estimated loss of earnings.

Comparison of workers removed from exposure with no breathlessness with those with an MRC breathlessness score of at least one showed a shorter time from first exposure to symptoms (48 $v 66$ months, $\mathrm{p}=0.07$ ) a significantly shorter time from symptoms to diagnosis (five $v 24$ months, $\mathrm{p}=0.003$ ) and a significantly higher baseline $\mathrm{FEV}_{1}$ in workers who had no breathlessness on removal from exposure $(90 \% v 73 \%$ predicted, $\mathrm{p}=0.008)$. These findings are in keeping with the studies by Chan-Yeung et $a l^{78}$ and Hudson $e t a l^{9}$ and suggest that workers diagnosed quickly after the development of symptoms are likely to recover the most.

\section{Conclusion}

The consequences of occupational asthma due to a variety of agents are considerable in terms of symptoms, lung function, and financial wellbeing. 
Diagnosis is often delayed. When removed from exposure symptoms do not completely resolve and abnormalities of lung function remain. Earlier diagnosis significantly influences the prospect of recovery.

Workers often remain exposed, however, and the reason may often be financial. Continued exposure means that symptoms are less likely to improve and their lung function is likely to deteriorate. In our opinion compensation should be directed at facilitating relocation and retraining rather than providing inadequate compensation for disability, which is difficult to assess in an asthmatic group.

Requests for reprints to: $\operatorname{Dr} P$ S Burge, Occupational Lung Disease Unit, East Birmingham Hospital, Bordesley Green East, Birmingham B9 5ST.

1 Adams WGF. Long term effects on the health of men engaged in the manufacture of toluene diisocyanate. $\mathrm{Br} \mathcal{F}$ Ind Med $1975 ; 32: 72-8$

2 Lozewicz S, Asoufi BK, Hawkins R, Newman Taylor AJ. Outcome of asthma induced by isocyanates. $B r \mathcal{F}$ Dis Chest 1987;81:14-22.

3 Paggiaro PL, Loi AM, Ferrante RB, Pardi F, Roselli MG Baschieri L. Follow up study of patients with respiratory disease due to TDI. Clin Allergy 1984;14:463-9.

4 Paggiaro PL, Bacci E, Dente FL, Talini D, Giuntini C. Prognosis of occupational asthma induced by isocyanates. Bull Eur Physiopath Respir 1988;23:565-9.

5 Burge PS. Occupational asthma in electronic workers caused by colophony fumes: follow up of affected workers. Thorax 1982;37:348-53.
6 Malo J-L, Cartier A, Ghezzo H, Lafrance M, McCants M, Lehrer SB. Patterns of improvement in spirometry, bronchial hyperresponsiveness, and specific IgE levels after cessation of exposure in occupational asthma caused by snow-crab processing. Am Rev Respir Dis 1988;138:807-12.

7 Chan-Yeung M, Lam S, Koener S. Clinical features and natural history of occupational asthma due to western red cedar (Thuja plicata). Am f Med 1982;72:411-5.

8 Chan-Yeung M, MacLean L, Paggiaro PL. Follow up study of 232 patients with occupational asthma caused by western red cedar. F Allergy Clin Immunol 1987;79:792.

9 Hudson P, Cartier A, Pineau L, Lafrance N, St Aubin JJ, Dubois JV, Malo J-L. Follow-up of occupational asthma caused by crab and various agents. $\mathcal{f}$ Allergy Clin Immunol 1985;76:682-8.

10 Pepys J. Occupational allergy due to platinum complex salts. Clinics in Immunology and Allergy 1984;4:131-58.

11 Baker DB, Gann PH, Brooks SM, Gallagher J, Bernstein IL. Cross-sectional study of platinum salt sensitization among precious metal refinery workers. Am f Ind Med 1990;18: 653-64.

12 Venables KM, Davidson AG, Newman Taylor AJ. Consequences of occupational asthma. Resp Med 1989;83: 437-40.

13 Rosenburg N, Garnier R, Rousselin X, Mertz R, Gervais P. Clinical and socio-professional fate of isocyanate induced asthma. Clinical Allergy 1987;17:55-61.

14 Yassi A. Health and socio-economic consequences of occupational respiratory allergies: a pilot study using workers compensation data. Am f Ind Med 1988;14:291-8.

15 Altman DG. Practical statistics for medical research. London: Chapman and Hall, 1991.

16 Industrial Injuries Advisory Council. Occupational asthma (Command 8121). London: HMSO, 1981.

17 Industrial Injuries Advisory Council. Occupational asthma (Command 9717). London: HMSO, 1986.

18 Industrial Injuries Advisory Council. Occupational asthma (Command 1244). London: HMSO, 1990.

19 Davies GE, Thompson AV, Niewola Z, Burrows GE, Teasdale EL, Bird DJ, Phillips DA. Allergy to laboratory animals: a retrospective and prospective study. $\mathrm{Br} \mathcal{F}$ Ind $\mathrm{Med}$ 1983;40:442-9.

Accepted 10 August 1992

\section{Destruction of manuscripts}

From 1 July 1985 articles submitted for publication will not be returned. Authors whose papers are rejected will be advised of the decision and the manuscripts will be kept under security for three months to deal with any inquiries and then destroyed. 